\title{
Evolution of Space Charges and Conductivity with DC Aging of Polyethylene-Synthetic and Natural Clay Composites
}

\author{
Mahmoud Abou-Dakka \\ Power Measurement Group, Institute of Measurement Science and Standards, National Research Council Canada, \\ 1200 Montreal Road Building, Ottawa, ON, Canada K1A 0R6 \\ Correspondence should be addressed to Mahmoud Abou-Dakka, mahmoud.abou-dakka@nrc-cnrc.gc.ca
}

Received 25 July 2012; Revised 9 November 2012; Accepted 11 November 2012

Academic Editor: Tianxi Liu

Copyright ( $\odot 2012$ Mahmoud Abou-Dakka. This is an open access article distributed under the Creative Commons Attribution License, which permits unrestricted use, distribution, and reproduction in any medium, provided the original work is properly cited.

\begin{abstract}
The evolution of the space charge and conductivity with DC poling of two types of polypropylene-(PP-) based nanocomposites (PNCs) was investigated. The PNCs were manufactured with different concentrations of synthetic and natural organoclays. The optimal concentrations of nanofiller that can efficiently mitigate the space charge with DC aging time were 2 -wt $\%$ for PPnatural-clay and between 2 and $4 \mathrm{wt} \%$ for the PP-synthetic-clay. Above these percentages charge transport through overlapping of nanoparticles can occur due to the interaction zone of double layers formed at the nanoparticle/host material interfaces. Under DC field the overlapping increases the conductivity of PNCs and minimizes the benefit of incorporating nanofillers into PP. The total charge stored in unfilled PP increased continuously with time reaching a maximum around $5000 \mathrm{~h}$ before decreasing but it also changed slightly in all filled specimens. It was perceived that the smaller the size of nanofiller platelets the more efficient the charge mitigation. The conductivity of specimens containing $6 \mathrm{wt} \%$ of natural clay and $8 \mathrm{wt} \%$ of synthetic clay reached $\approx 6$ times the level of the unfilled PP. This observation could be related and due to the crossing of the percolation threshold for these composites.
\end{abstract}

\section{Introduction}

Polymers such as polypropylene (PP) are extensively used as electrical insulation in power capacitors, cable wraps, and phase separators for rotating electrical equipment. The impact of filling polymers with a small quantity of nanoparticles is currently the most active subject of research for universities, research centers, and industrial institutions. The main objective of these activities is to develop the next highperformance industrial materials with superior properties compared to unfilled polymers. This can only be realized if the resulting polymer nanocomposites (PNCs) possess as many as possible of the following features: more discharge endurance, better thermal and mechanical properties, lower quantity of accumulated space charges, longer lifetime, and so forth.

It was reported that the mechanical and thermal properties of polypropylene (PP) [1-3] and Epoxy resin [4] were improved after being loaded with a small weight percentage (wt\%) of organoclay. The electrical breakdown strength, surface and volume resistivity to erosion and Partial Discharges (PDs) were superior to the unfilled materials [5-8]. It was also stated that the polyamide-aluminum-nitride composites are more tolerant to high working temperatures [9]. In addition to that, polymer materials can provide new functions such as gas barrier and flame resistance $[10,11]$ due to the effects of clay dispersion.

Less accumulation of space charge in the insulation material allows for applying higher field at the same insulation thickness, which could decrease the weight and cost of power equipment. Therefore, understanding the real impact of filling polymers with nanoparticles on space charge evolution with aging time is absolutely critical for developing new composites for high-voltage applications.

Compatibilizers are normally used for making the interaction of PP and nanoclay more favourable $[2,12]$ to form PNCs with higher degrees of exfoliation of nanoparticles within the matrix of PP. The effect of the compatibilizers on the space charge profile and quantity will be examined. 
It was observed that the quantity of space charges was substantially reduced by adding a few wt $\%$ of nanoparticles to the polyethylene and polypropylene $[13,14]$. Clay platelets limit the molecular motion in the amorphous phase because of the interaction between the platelets and PP matrix [15]. In other words the interface between nanoparticles and neighbouring materials can control the carrier transport, which is closely related to the charge injection [16]. Small quantities of nanoparticles could mitigate charge injection (or charge trapping) and slow down material degradation [17]. However, excessive quantities of nanofiller could lead to losing this advantage. This could be due to the overlapping of nanoparticles after crossing the material percolation threshold [18].

In this work the following two types of organoclay were incorporated in the isotactic polypropylene (PP): Topy synthetic tetrasilisic mica from Topy Co., Ltd. and Cloisite 20A powder of Wyoming natural montmorillonite clay from Southern Clay Products. The concentration of nanoparticles was between $1 \mathrm{wt} \%$ and $8 \mathrm{wt} \%$. Measurements of the evolution of space charge density and conductivity during more than $11000 \mathrm{~h}$ of DC poling at $-25 \mathrm{kV} / \mathrm{mm}$ were performed. This could lead us to define the optimal concentration of nanoclay at which the PNC space charge mitigation is at a maximum. This could set up the base for developing the next generation of advanced insulation materials with high performance for power capacitors and different high-voltage electrical applications.

\section{Experimental}

The tested specimens were composed of two sets of PNCs. The first set was composed of an isotactic PP (Profax HL$451 \mathrm{H}$ from Basell) filled with different wt $\%$ of Topy synthetic tetrasilisic mica from Topy Co., Ltd. of Japan. This set was prepared for a collaboration project between the Industrial Materials Institute (IMI) and the Institute for National Measurement Standards (INMS) of the NRC to develop nanocomposite insulations for high-voltage capacitor applications. The second set was composed of the same PP material but filled with a different quantity of Cloisite natural montmorillonite clay from Wyoming. However, this set was manufactured for a project within the Versailles Project on Advanced Materials and Standards (VAMAS), Technical Working Area 33 (TWA-33) concerned with the development of test methods for chemical, morphological, mechanical, and electrical characterization techniques for polymer nanocomposites. VAMAS is an international organization that supports world trade in high technology [19]. Detailed information about the chemical structures of the natural and synthetic clays and the method of preparation of the synthetic clays is described in [20-22].

2.1. Preparation of the PP Nanocomposite. The preparation of nanocomposites was carried out in the following steps [23].

Step 1 (Preparation of the Master Batch (MB)). The base PP material was melt compounded with a $1: 1$ mixture of two compatibilizers-PP grafted with maleic anhydride (PPMA) from Eastman (Epolene 3015) and from Chemtura (Polybond 3150), antioxidant Irganox B-225 (from Ciba), and one of the organoclays. The compounding was carried out at $200^{\circ} \mathrm{C}$ under a blanket of dry nitrogen in a twinscrew extruder (TSE; Leistritz $34 \mathrm{~mm}, L / D=40$; high shear intensity screw, speed: $200 \mathrm{rpm}$; throughput: $5 \mathrm{~kg} / \mathrm{h}$ ). The resulting composition of both materials subjected to test can be seen in Table 1.

Step 2 (Dilution of MB). Samples containing 0, 1, 2, 4, and $8 \mathrm{wt} \%$ of synthetic clay from Topy and 0,2 , and $6 \mathrm{wt} \%$ of natural clay (Cloisite 20A) were prepared. To ascertain the same compounding history of the samples all samples were extruded at $180^{\circ} \mathrm{C}$ under a blanket of dry nitrogen, using the same TSE with the same processing parameters as used for both MBs. Thus, PP + antioxidant was extruded twice. The MBs obtained in Step 1 were reextruded, and the other compositions were prepared by first dry-blending preextruded PP with each MB at an appropriate ratio and then reextruding the blend. The clay dispersion parameters for the synthetic and natural clay-based samples were (1) the interlayer spacing $d_{001}: 3.45$ for synthetic clay and $2.8 \pm$ $0.2 \mathrm{~nm}$ for natural clay, (2) the number of platelets in the residual stacks: 2.64 for Topy and $3.1 \pm 0.2 \mathrm{~nm}$ for Cloisite $20 \mathrm{~A}$, and (3) the degree of exfoliation: $88 \%$ for synthetic clay and $\sim 50 \%$ for Cloisite $20 \mathrm{~A}$.

Step 3 (Preparation of films). The pelletized dried compositions obtained in Step 2 were film blown at $T=180$ to $230^{\circ} \mathrm{C}$ into films with an approximate thickness of $135 \pm 7 \mu \mathrm{m}$. Subsequently, the films were rolled twice at $115^{\circ} \mathrm{C}$ between 3 rolls in a Metaplast calendar, to obtain the final specimens for testing.

2.2. Specimens. The percentage of nanofillers, the composition and names of each type of specimens used in this paper are given in detail in Table 1. The two PP host materials PP1$0 \%$ (base PP for the PNC with synthetic clay) and PP2-0\% (base PP for the PNC with natural clay) only defer from each other by the percentage of compatibilizers $(17.4 \%$ and $12.8 \%$, resp.).

The filled specimens are referred to in this paper as "PP1+S $x \%$ " if they contain synthetic clay and "PP2 $+\mathrm{N} y \%$ " if they contain natural clay. $x \%$ and $y \%$ indicate the percentages by weight content of Topy and Cloisite organoclay, respectively.

The individual platelets' aspect ratios were around 6000 and 286 for synthetic and natural clay, respectively [21-23].

2.3. Space Charge and Conductivity Measurements. Space charge measurements were performed using the Five Labs Pulse Electroacoustic (PEA) measurement system [24] having a resolution of $\sim 15 \mu \mathrm{m}$ and Tektronix $7404,4 \mathrm{GHz}$, and $20 \mathrm{GS} / \mathrm{s}$ digital oscilloscope. The DC conductivity was measured with a Keithley 6517B electrometer.

During the PEA and conductivity tests, a thin layer of silicon oil was applied on each side of the sample to ensure 
TABLE 1: PNC compositions for both sets of tested specimens. Synthetic for NPC filled with nanoclays from Topy and natural for PNC filled with Cloisite 20A.

\begin{tabular}{lcccc}
\hline Given name & PP (\%) & Antioxidants (\%) & Compatibilizer (\%) & \multicolumn{2}{c}{$\begin{array}{c}\text { Nanoclay } \\
\text { Type }\end{array}$} \\
\hline PP1-0\% & 82.4 & 0.2 & 17.4 & 0 \\
PP2-0\% & 87.0 & 0.2 & 12.8 & 0 \\
PP1-S1\% & 81.6 & 0.2 & 17.2 & 1 \\
PP1-S2\% & 80.7 & 0.2 & 17.1 & 2 \\
PP1-S4\% & 79.1 & 0.2 & 16.7 & 4 \\
PP1-S8\% & 75.8 & 0.2 & 16 & 8 \\
PP2-N2\% & 85.3 & 0.2 & 12.5 & Synthetic \\
PP2-N6\% & 81.8 & 0.2 & 12 & Synthetic \\
\hline
\end{tabular}

a good contact between the specimen and the electrodes. A $0.2 \mathrm{~mm}$ thick, $30 \mathrm{~mm}$ diameter semicon disk was inserted between the specimen and the upper brass electrode during DC poling. Specimen poling and conductivity measurements were performed at the same field, $-25 \mathrm{kV} / \mathrm{mm}$ DC. However, the PEA measurements were performed at $4 \mathrm{kV} / \mathrm{mm}$ and performed first on fresh specimens ( $0 \mathrm{~h}$ of DC poling) to be used as a reference and then after 168 h, 336 h, 1008 h, 2016 h, $3024 \mathrm{~h}, \ldots, 11088 \mathrm{~h}$ of poling time.

Up to three specimens were tested for each condition, and the average of the conductivity and the total charge $(Q)$ between both electrodes was performed to calculate the total charge $Q$. The value of the total charge was the integral of the absolute value of charges in the specimens' volume, that is, between both electrodes.

\section{Results and Discussion}

3.1. Space Charge Distribution Measurements. The figures representing the distribution of space charge depict the cathode, to which the $-25 \mathrm{kV} / \mathrm{mm}$ DC field was applied, on the right side and the anode on the left side.

The double injection of charges (homocharges) is clearly observed in Figure 1 for the unfilled material PP1-0\%. This figure shows that the quantity of injected negative charge is higher from the cathode compared to anode (ground). Figure 1 illustrates that the injected charge peaks increase with poling time and move deeper towards the central area of the specimen. This in turn leads to the increase of the local electric field in the sample's bulk. It seems that the charge injection is stabilized and even tends to decrease after $5040 \mathrm{~h}$ of aging.

Figure 2 shows the space charge distribution in the second PP base material for PNC with natural clay, PP2$0 \%$. This figure demonstrates antisymmetric peaks of homocharges built-up from both electrodes. The amplitude of these peaks increases and advances deeper into the specimen bulk. After $3024 \mathrm{~h}$ of aging, the amplitude decreases, and the advance towards the central area continued.

The two types of base materials PP1-0\% and PP2-0\% only differ from each other by the percentage of compatibilizers (see Table 1). It is observed from Figures 1 and 2 that both materials accumulate significant charges and considerable differences between them in the quantity and profile

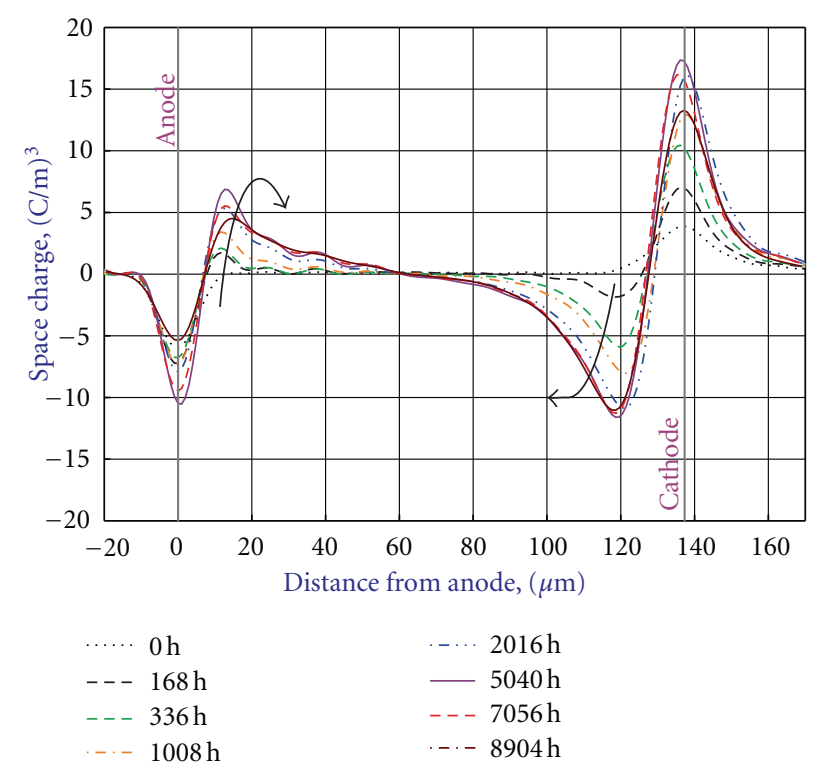

Figure 1: Effect of the poling time at $-25 \mathrm{kV} / \mathrm{mm}$ DC field on space charge distributions in PP1-0\%.

of charge. The nature and effect of compatibilizers were intensively studied $[14,15,25]$. Since both PP and clays are nonpolar materials, their compatibility to form PNCs with good dispersion of nanoclay in the PP matrix is very low. Therefore, chemical coupling agents will be required to make the interaction of the PP and nanoparticles more favourable to ensure better dispersion of nanoclay in the PP matrix. These agents are so-called compatibilizers. Optimal quantities of compatibilizers lead to better degrees of exfoliation and more homogeneous distributions of nanoparticles in the matrix of PP. This can improve the ability of the resultant PNC to mitigate the space charges. Thus, the optimal percentage of compatibilizers could be a very useful subject of investigation in the future.

Just by loading PP1-0\% with 1 wt $\%$ of synthetic clay (PP1-S1\%), the value and profile of the charges are dramatically changed, see the distribution of charges in Figures 1 and 3. The injected charges from the cathode were substantially reduced compared to the unfilled material, and the majority 

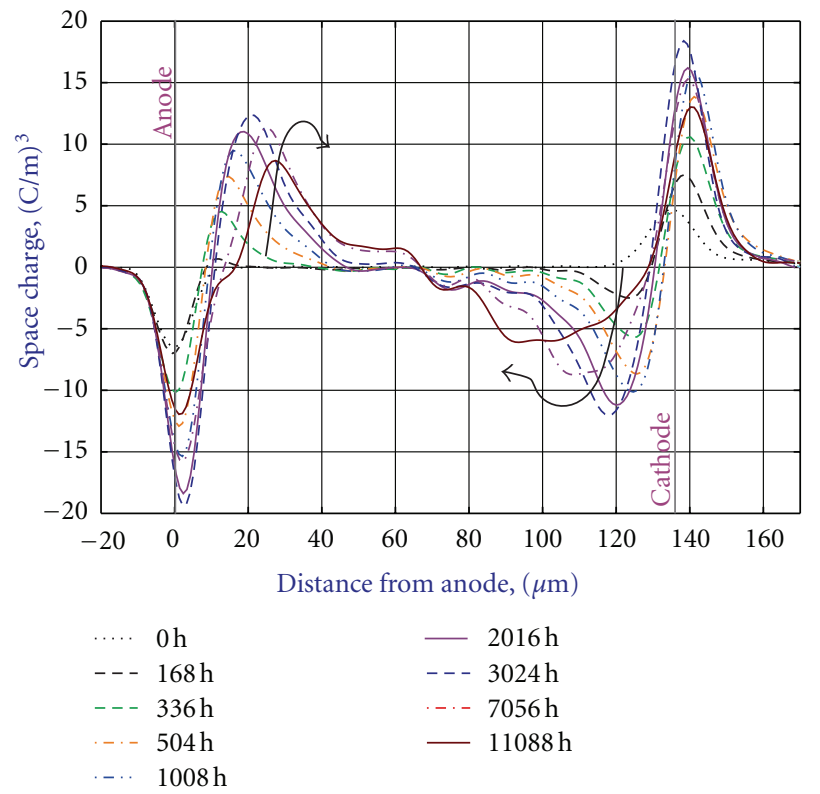

FIGURE 2: Effect of the poling time at $-25 \mathrm{kV} / \mathrm{mm}$ DC field on space charge distributions in PP2-0\%.

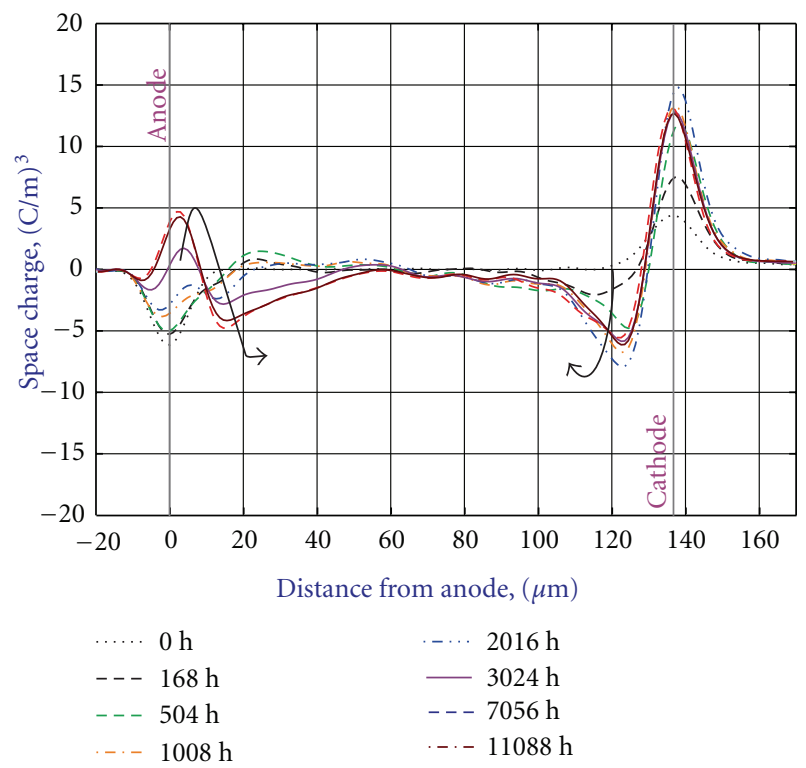

Figure 3: Effect of the poling time at $-25 \mathrm{kV} / \mathrm{mm}$ DC field on space charge distributions in PP-S1\%.

of the homocharges in the vicinity of the anode were mitigated and replaced by heterocharges. With aging time the homocharges were substantially mitigated, and a small quantity of heterocharges are still located in the vicinity of anode.

Two wt $\%$ of synthetic clay, PP1-S2\%, was able to mitigate the majority of charges in the central zone of the specimens as shown in Figure 4. The amplitude of space charge peaks near the anode decreased with poling time for PP1-S2\%, while it increased for the PP1-0\%. A small increase of

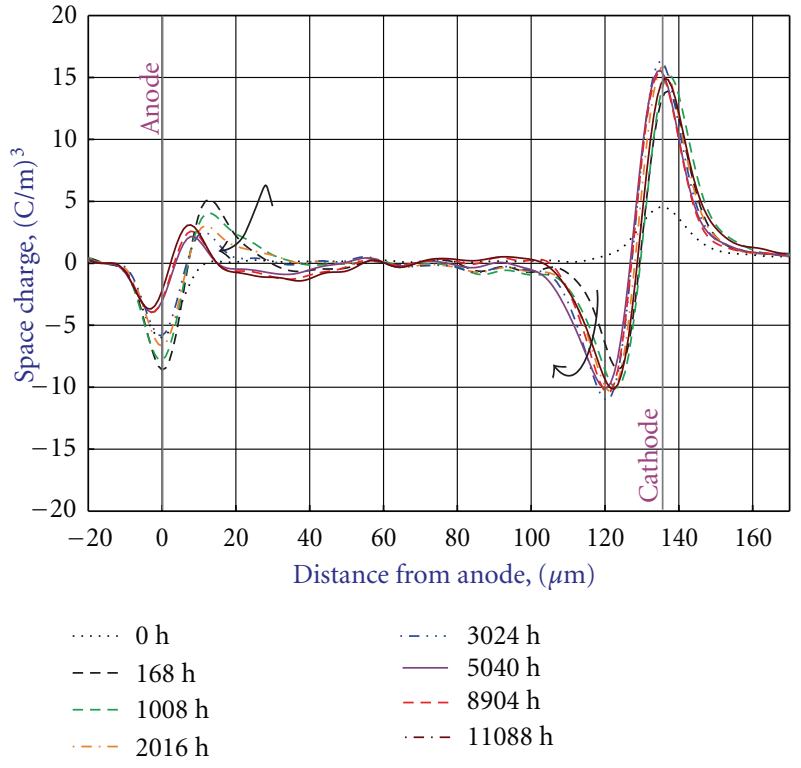

FIgURE 4: Effect of the poling time at $-25 \mathrm{kV} / \mathrm{mm}$ DC field on space charge distributions in PP-S2\%.

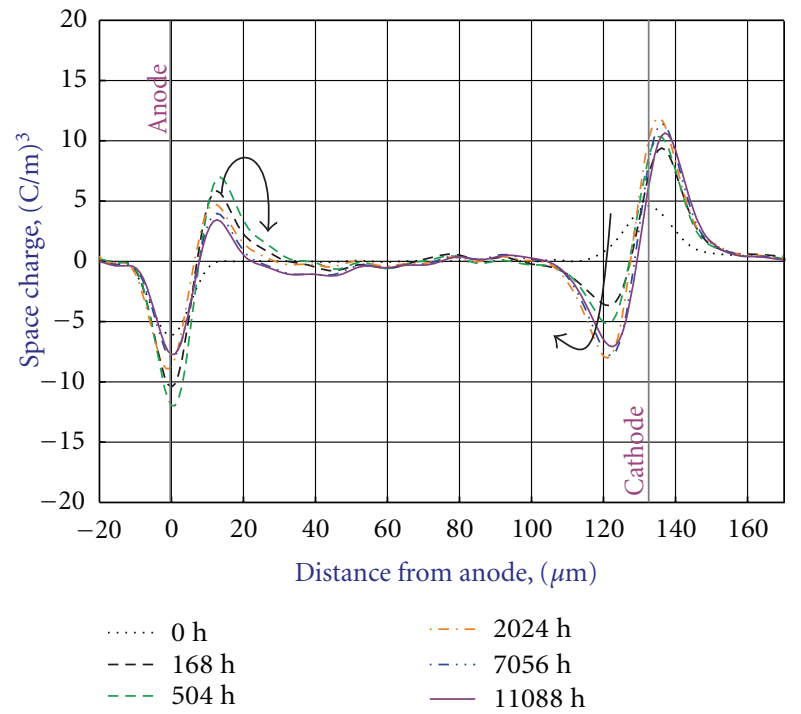

FIGURE 5: Effect of the poling time at $-25 \mathrm{kV} / \mathrm{mm}$ DC field on space charge distributions in PP-S4\%.

homocharge close to the cathode is observed. This is illustrated by the arrow in Figure 4. The low quantity of charge in the central zone is only slightly changed after $11088 \mathrm{~h}$ of DC poling.

Increasing the synthetic nanofiller content to $4 \mathrm{wt} \%$ further decreases the amount of charge, especially in the central area (Figure 5).

When the PP1-0\% is loaded with 8 wt $\%$, sample PP1S8\%, significant charge build-up was observed in the central area, see Figure 6. It was previously reported that the concentration of charges in the central zone was a sign of degradation of the specimens' condition [26]. 


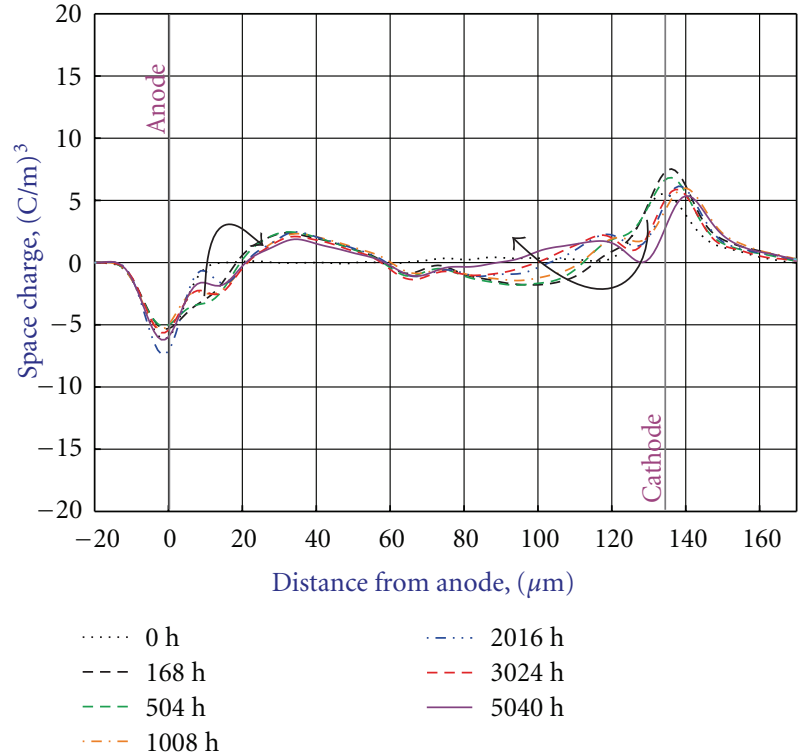

Figure 6: Effect of the poling time at $-25 \mathrm{kV} / \mathrm{mm}$ DC field on space charge distributions in $\mathrm{PP}-\mathrm{S} 8 \%$.

Hence, from the results shown above, the optimal percentage for the synthetic filler seems to be between 2 and $4 \mathrm{wt} \%$.

The addition of $2 \mathrm{wt} \%$ of natural clay, PP2-N2\%, results in decreasing the charges all over the sample bulk as depicted in Figure 7. Similar to what it was observed above for PP1-S2\% (Figure 3), the small homocharges' peaks in this composition decrease with the poling time at the anode side. The charges in the central zone were very small and independent of poling time. Although PP1-S2\%, PP1-S4\%, and PP2-N2\% were all able to suppress charges in the central zone, PP2-N2\% was the most effective. As shown in [26], the amount of space charge in the central zone of a sample affects its life-time.

Loading PP with $6 \mathrm{wt} \%$ of natural clay as shown in Figure 8 also leads to build-up charges in the sample's central zone. Thus, charge accumulation in the central area of the specimens could generate a high local electric field in that zone, sharply increase conductivity, which leads to the degradation of the specimen condition with time.

Electric field distributions after $5040 \mathrm{~h}$ of aging with $-25 \mathrm{kV} / \mathrm{mm}$ DC are depicted in Figure 9. They show higher fields in the specimens' central zone for PP2-N6\% and PPS8\% than for PP1-S2\% and PP2-N2\%. One of the PP-S8\% specimens failed after $2016 \mathrm{~h}$, and two PP2-N6\% specimens failed after $6384 \mathrm{~h}$ and $7056 \mathrm{~h}$, indicating some correlation between higher local electric fields in the sample with high concentrations of fillers and shorter times to breakdown. None of the samples containing $2 \mathrm{wt} \%$ or $4 \mathrm{wt} \%$ of PNC with synthetic nanoclay or $2 \mathrm{wt} \%$ of the PNC with natural nanoclay failed after $11088 \mathrm{~h}$ of a DC field poling.

Figure 10 illustrates the charge distribution in the two types of host materials PP1-0\% and PP2-0\% and PP1-S2\% and PP2-N2\% after $11088 \mathrm{~h}$ of aging. The peaks of charges

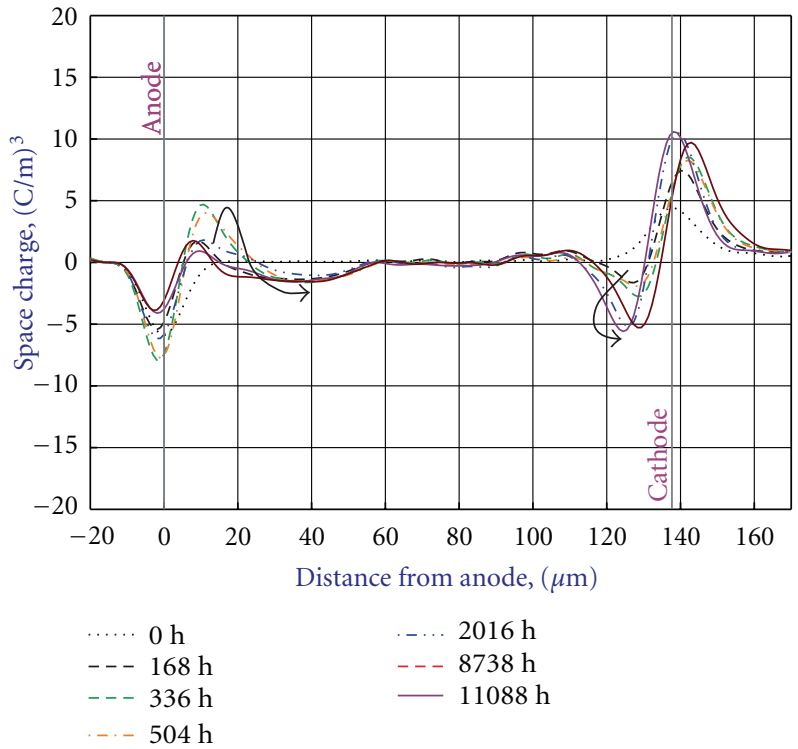

FIGURE 7: Effect of the poling time at $-25 \mathrm{kV} / \mathrm{mm}$ DC field on space charge distributions in PP-N2\%.

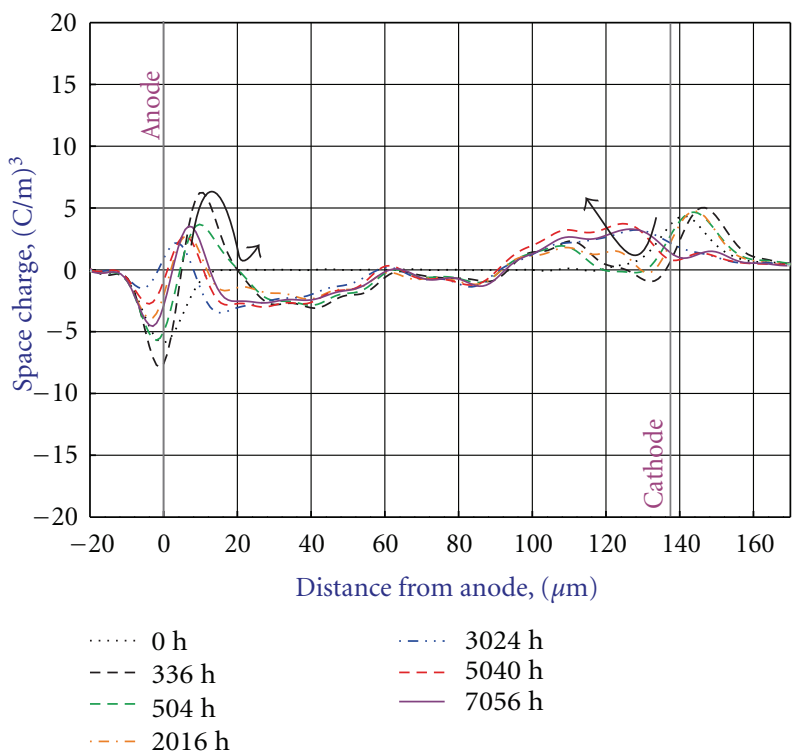

FIGURE 8: Effect of the poling time at $-25 \mathrm{kV} / \mathrm{mm}$ DC field on space charge distributions in PP-N6\%.

are much higher and deeply extended into the central areas for the host materials compared to both filled materials. Lower charges in the PNC with natural clay, PP2-N2\%, compared to the PNC with synthetic clay, PP1-S2\% are also observed. This fact could be related to the ratio of the individual dimensions of the filler nanoplatelets. The individual platelets' aspect ratios were $\leq 6000$ and $\approx 286$ for synthetic and natural, respectively $[20,23]$. The smaller the nanoplatelets the larger the interfacial interaction zone between nanoparticles and the host material. Therefore PP2-N2\% would block charge injection more efficiently than PP1-S2\% 


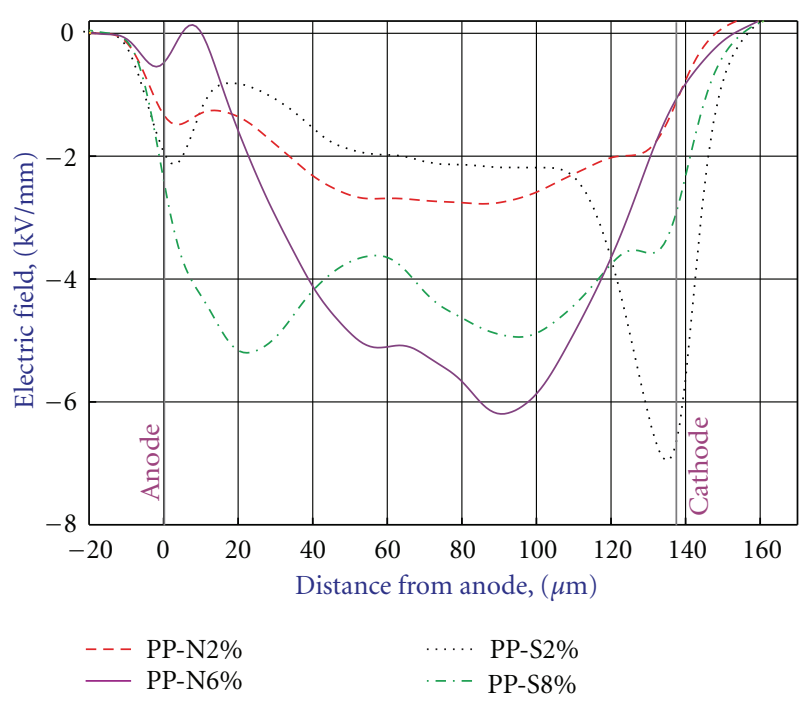

Figure 9: Electric field distributions after $5040 \mathrm{~h}$ of DC poling at $-25 \mathrm{kV} / \mathrm{mm}$.

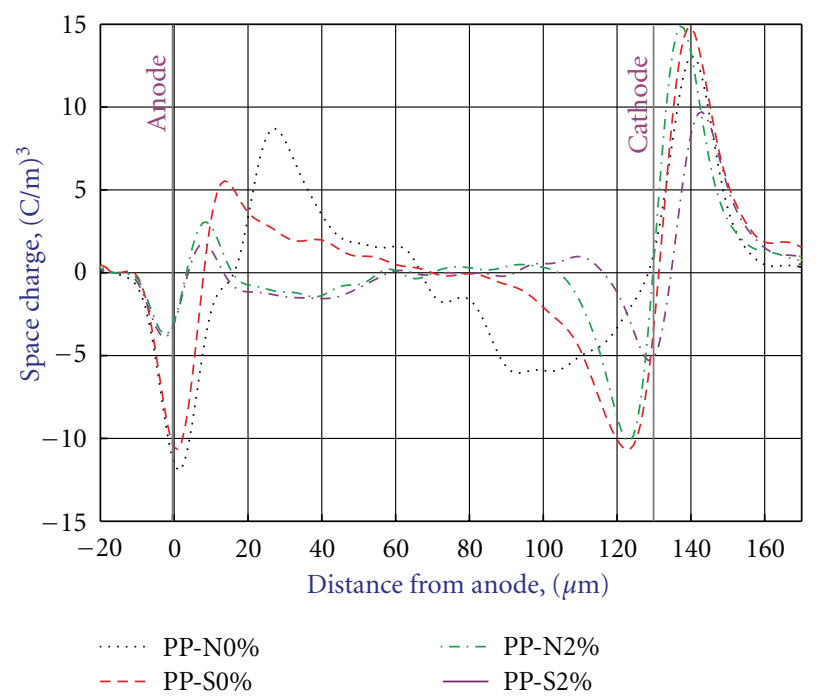

FIgURE 10: Space charge distributions after $66 \mathrm{~W}$ of DC poling at $-25 \mathrm{kV} / \mathrm{mm}$ for the unfilled and filled with $2 \mathrm{wt} \%$ of natural and synthetic clay.

(Figures 3 and 7). These results are in agreement with the findings of other research groups $[6,18,27]$.

As the concentration of nanofillers increases over the percolation threshold the interaction zones, or Gouy-ChapmanStern layers, which are highly conductive, could overlap, and the overall conductivity of the composites considerably increases $[28,29]$.

The integral of the absolute value of charges measured with the PEA technique between both electrodes gives the total charge, $Q$, stored in a sample. When $Q$ is plotted versus time on a logarithmic scale, both unfilled materials demonstrate a dramatic increase of charges with aging time, see Figure 11. However, all the filled specimens showed steady values of $Q$ with time, and the lowest accumulated $Q$ was

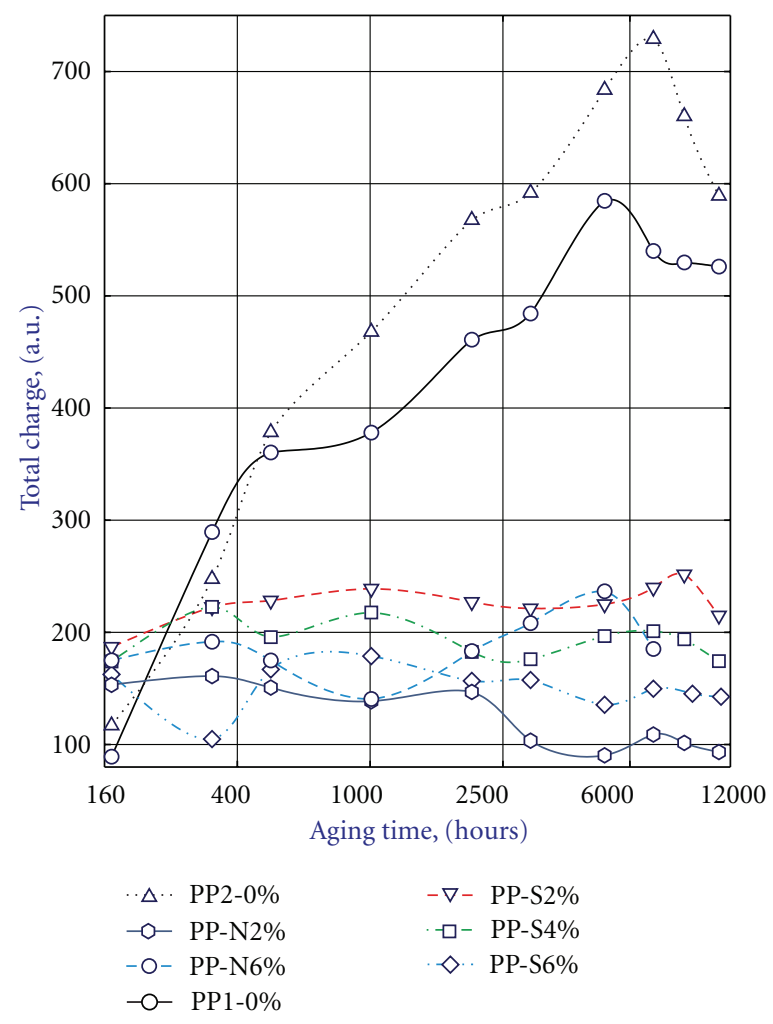

Figure 11: Total charge, Q, versus poling time for PPs and their nanocomposites. Effect of the organoclay type and concentration.

observed in PP2-N2\%. Note that for poling times shorter than $\sim 300 \mathrm{~h}$ all nanocomposites exhibit a higher quantity of charge than PP1-0\% and PP2-0\%. Short poling times may not reveal the real advantage of the nanocomposite structures compared with unfilled polymer. At least $\approx 1000 \mathrm{~h}$ of poling time is required to clearly see the benefit of incorporating nanoparticles in PP material on charge mitigation characteristics.

3.2. Conductivity Measurements. Figure 12 shows the conductivity measurement results. The base material, PP2-0\%, has the lowest conductivity. For the same particle concentration synthetic clay gives lower conductivity than the composite with natural clay. This could be due to impurities in the natural clay such as iron, dolomite, and gypsum, especially in the presence of moisture. The increase of nanoclay concentration increases conductivity for both types of PNC. PP2-N6\% and PP1-S8\% showed almost 6 times higher conductivity than PP2-0\% (for convenience only PP2$0 \%$ is drawn in the figure).

The lowest value of the conductivity was observed for PP2-0\% despite having the highest quantity of accumulated charge, which could be due to deeply trapped charges. The applied field of $-25 \mathrm{kV} / \mathrm{mm}$ DC during the conductivity measurements would not be high enough to free these charges from their deep traps.

It is to be noted that the conductivity tends to increase after $5000 \mathrm{~h}$, and more tests and longer poling time are 


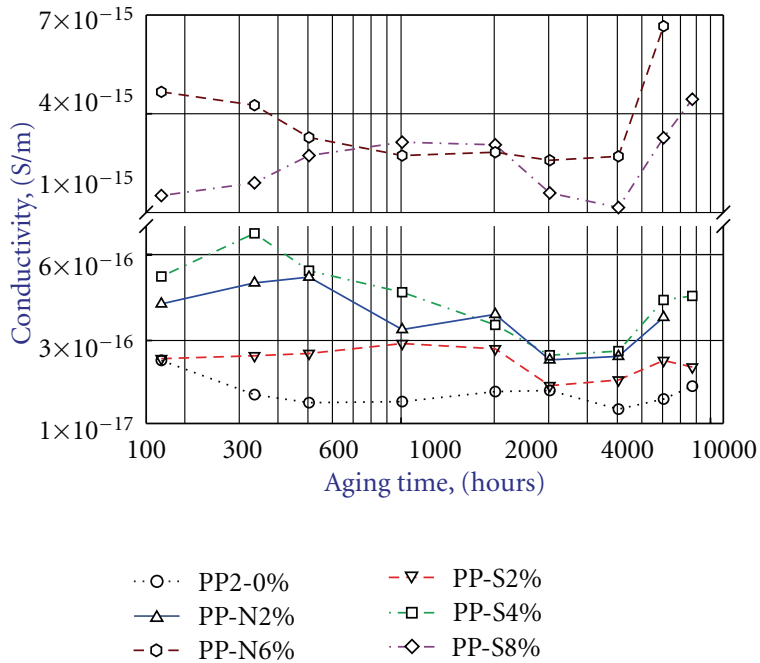

FIGURE 12: The effect of nanoparticle concentration DC conductivity measured at $-25 \mathrm{kV} / \mathrm{mm}$.

required to better understand the effect of DC field on space charge effects in polymer nanocomposites.

The high conductivity of the PP-S8\% and the PPN6\% could be due to overlapping of the interaction zones around nanoparticles, which could lead to a dominant charge transport process throughout the system via the charge double layers [28-30].

In summary, from all results presented above it is clear that the clay platelets limit the molecular motion in the amorphous phase. This happens because of the interaction between the platelets and PP matrix [15]. In other words the interface between nanoparticles and neighbouring materials can control carrier and electric transport properties, which are closely related to the charge injection, retention, and bulk dynamics [16]. Hence, nanoparticles can change the depth and density of traps, which in turn change the density and mobility of space charge. From another point of view, it is probable that the interface could not be simply charge sources but the seats of progressive chemical, mechanical, and electrical degradation [31]. Small quantities of nanoparticles could mitigate charge injection (or charge trapping) and slow down material degradation [17]. However, an excessive quantity of nanofillers makes the distance between the adjacent platelets short enough to trigger local percolation processes. This depends on the aspect ratio of the platelets. The higher the aspect ratio for the synthetic nanoclay is, the higher the probabilities of percolation and overlapping of nanoparticles are $[17,18,32]$.

\section{Conclusions}

The evolution of space charge density and quantity as well as the conductivity with DC poling in PP-based nanocomposites containing natural and synthetic organoclays was investigated.
PP material can be affected by the manufacturing process where the percentage of compatibilizers can lead to different space charge evolution.

It was observed that loading PP with certain low percentages per weight of nanoclay can efficiently mitigate space charges. The optimal concentration of clay was $2 \mathrm{wt} \%$ for the PNCs with natural clay and between 2 and $4 \mathrm{wt} \%$ for PNCs with synthetic clay.

The accumulated space charge in PP1-0\% and PP2-0\% increases continuously with time of DC poling until $5000 \mathrm{~h}$. In contrast, both nanofilled composites are almost independent of poling time.

At least $1000 \mathrm{~h}$ of DC poling is needed to clearly see the benefit of charge mitigation in PNC specimens.

Samples containing natural clay had less space charge than the samples containing synthetic clay. This behaviour could be related to the difference in the individual platelets' aspect ratios of the synthetic and natural organoclays.

The high conductivity of PP1-S8\% and PP2-N6\% could be related to excessive nanoparticle concentrations that may increase the overlapping of the diffused double-layer charge clouds and promote charge transport throughout those layers. To obtain the best results of filling PP with nanoclays, the nanoclay's wt $\%$ incorporated in the PP materials should be less than the percolation threshold.

\section{Acknowledgments}

The authors express many thanks to Dr. L. A. Utracki of the Industrial Materials Institute of NRC Canada for providing nanocomposite specimens for this work. They also gratefully acknowledge the technical help of Mrs. Y. Chen of the Institute for National Measurement Standards, NRC Canada.

\section{References}

[1] T. S. Ellis and J. S. D’Angelo, "Thermal and mechanical properties of a polypropylene nanocomposite," Journal of Applied Polymer Science, vol. 90, no. 6, pp. 1639-1647, 2003.

[2] E. Manias, A. Touny, L. Wu, K. Strawhecker, B. Lu, and T. C. Chung, "Polypropylene/montmorillonite nanocomposites. Review of the synthetic routes and materials properties," Chemistry of Materials, vol. 13, no. 10, pp. 3516-3523, 2001.

[3] W. Wenyi, Z. Xiaofei, W. Guoquan, and C. Jianfeng, "Preparation and properties of polypropylene filled with organomontmorillonite nanocomposites," Journal of Applied Polymer Science, vol. 100, no. 4, pp. 2875-2880, 2006.

[4] P. B. Messersmith and E. P. Giannelis, "Synthesis and characterization of layered silicate-epoxy nanocomposites," Chemistry of Materials, vol. 6, no. 10, pp. 1719-1725, 1994.

[5] N. Fuze, T. Tanaka, and Y. Ohki, "Evolution of dielectric properties in polyethylene/clay nanocomposites," in Proceedings of the Conference on Electrical Insulation and Dielectric Phenomena (CEIDP '09), pp. 507-510, Virgina Beach, Va, USA, October 2009.

[6] J. K. Nelson and Y. Hu, "Nanocomposite dielectrics-properties and implications," Journal of Physics D, vol. 38, no. 2, pp. 213-222, 2005.

[7] M. Kozako, N. Fuse, Y. Ohki, T. Okamoto, and T. Tanaka, "Surface degradation of polyamide nanocomposites caused by 
partial discharges using IEC (b) electrodes," IEEE Transactions on Dielectrics and Electrical Insulation, vol. 11, no. 5, pp. 833839, 2004.

[8] T. Tanaka, "Interface properties and surface erosion resistance," in Dielectric Polymer Nanocomposites, K. Nelson, Ed., pp. 229-258, Springer Science and Business Media, 2010.

[9] Y. Dimitrienko, "Modelling of the mechanical properties of composite materials at high temperatures: part 1. Matrix and fibers," Applied Composite Materials, vol. 4, no. 4, pp. 219-237, 1997.

[10] K. Yano, A. Usuki, A. Okada, T. Kurauchi, and O. Kamigaito, "Synthesis and properties of polymide-clay hybrid," Journal of Polymer Science A, vol. 31, no. 10, pp. 2493-2498, 1993.

[11] J. Zhu, A. B. Morgan, F. J. Lamelas, and C. A. Wilkie, "Fire properties of polystyrene-clay nanocomposites," Chemistry of Materials, vol. 13, no. 10, pp. 3774-3780, 2001.

[12] C. Ding, H. He, B. Guo, and D. Jia, "Structure and properties of polypropylene/clay nanocomposites compatibilized by solid-phase grafted polypropylene," Polymer Composites, vol. 29 , no. 6, pp. 698-701, 2008.

[13] K. Nelson, "The promise of dielectric nanocomposites," in Proceedings of the IEEE International Symposium on Electrical Insulation (ISEI' 06), pp. 452-457, Toronto, Canada, June 2006.

[14] M. Abou Dakka, A. Bulinski, and S. S. Bamji, "Space charge evolution in polypropylene containing synthetic and natural organoclays," in Proceedings of the Annual Report Conference on Electrical Insulation and Dielectric Phenomena (CEIDP '10), Indiana, Ind, USA, October 2010.

[15] J. I. Velasco, M. Ardanuy, V. Realinho et al., "Polypropylene/clay nanocomposites: combined effects of clay treatment and compatibilizer polymers on the structure and properties," Journal of Applied Polymer Science, vol. 102, no. 2, pp. 12131223, 2006.

[16] M. F. Fréchette and C. W. Reed, "The role of molecular dielectrics in shaping the interface of polymer nanodielectrics," in Proceedings of the Annual Report Conference on Electrical Insulation and Dielectric Phenomena (CEIDP '07), pp. 279-285, Vancouver, Canada, October 2007.

[17] T. J. Lewis, "Interfaces: nanometric dielectrics," Journal of Physics D, vol. 38, no. 2, pp. 202-212, 2005.

[18] E. J. Garboczi, K. A. Snyder, J. F. Douglas, and M. F. Thorpe, "Geometrical percolation threshold of overlapping ellipsoids," Physical Review E, vol. 52, no. 1, pp. 819-828, 1995.

[19] http://www.vamas.org/twa33/index.html.

[20] L. A. Utracki, M. Sepehr, and E. Boccaleri, "Synthetic, layered nanoparticles for polymeric nanocomposites (PNCs)," Polymers for Advanced Technologies, vol. 18, no. 1, pp. 1-37, 2007.

[21] http://www.scprod.com/product_bulletins/PB\%20Cloisite\% 2020A.pdf.

[22] L. A. Utracki, "Clay-containing polymeric nanocomposites and their properties," IEEE Electrical Insulation Magazine, vol. 26, no. 4, pp. 6-15, 2010.

[23] A. Bulinski, S. S. Bamji, M. Abou-Dakka, and Y. Chen, "Dielectric properties of polypropylene containing synthetic and natural organoclays," in Proceedings of the IEEE International Symposium on Electrical Insulation (ISEI '10), San Diego, Calif, USA, June 2010.

[24] Y. Li, M. Yasuda, and T. Takada, "Pulsed electroacoustic method for measurement of charge accumulation in solid dielectrics," IEEE Transactions on Dielectrics and Electrical Insulation, vol. 1, no. 2, pp. 188-195, 1994.
[25] P. Reichert, H. Nitz, S. Klinke, R. Brandsch, R. Thomann, and R. Mulhaupt, "Poly(propylene)/organoclay nano-composites formation: Influence of compatibilizer functionality and organoclay modification," Macromolecular Materials and Engineering, vol. 275 , no. 1, pp. 8-17, 2000.

[26] M. Abou-Dakka, A. Bulinski, and S. Bamji, "Space charge development and breakdown in XLPE under DC field," IEEE Transactions on Dielectrics and Electrical Insulation, vol. 11, no. 1, pp. 41-49, 2004.

[27] G. Chen, J. T. Sadipe, Y. Zhuang, C. Zhang, and G. C. Stevens, "Conduction in linear low density polyethylene nanodielectric materials," in Proceedings of the IEEE 9th International Conference on the Properties and Applications of Dielectric Materials (ICPADM '09), pp. 845-848, Harbin, China, July 2009.

[28] T. J. Lewis, "Interfaces are the dominant feature of dielectrics at the nanometric level," IEEE Transactions on Dielectrics and Electrical Insulation, vol. 11, no. 5, pp. 739-753, 2004.

[29] J. K. Nelson and J. C. Fothergill, "Internal charge behaviour of nanocomposites," Nanotechnology, vol. 15, no. 5, pp. 586-595, 2004.

[30] J. C. Fothergill, "Ageing, space charge and nanodielectrics: ten things we don't know about dielectrics," in Proceedings of the International Conference on Solid Dielectrics (ICSD '07), pp. 110, Winchester, UK, July 2007.

[31] T. J. Lewis, "Nanometric dielectrics," IEEE Transactions on Dielectrics and Electrical Insulation, vol. 1, no. 5, pp. 812-825, 1994.

[32] D. Fabiani, G. C. Montanari, and L. Testa, "Effect of water adsorption on the dielectric propertiesof nanostructured insulating materials," IEEE Transactions on Dielectrics and Electrical Insulation, vol. 15, pp. 118-126, 2009. 

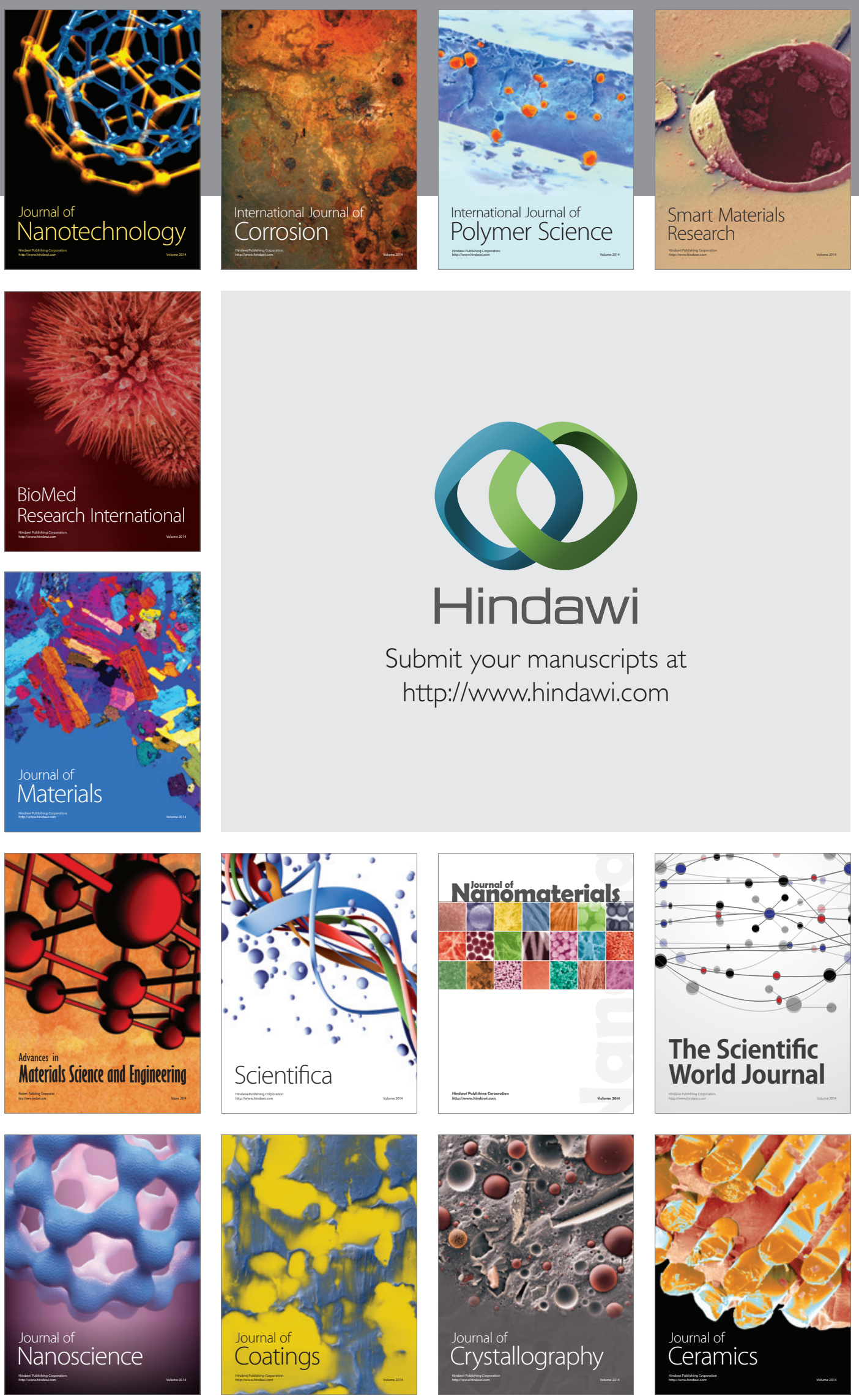

The Scientific World Journal

Submit your manuscripts at

http://www.hindawi.com

\section{World Journal}

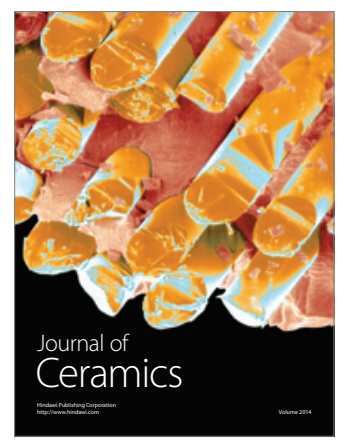

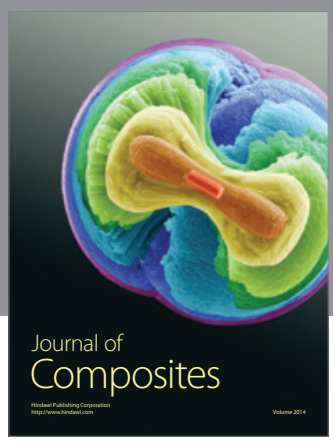
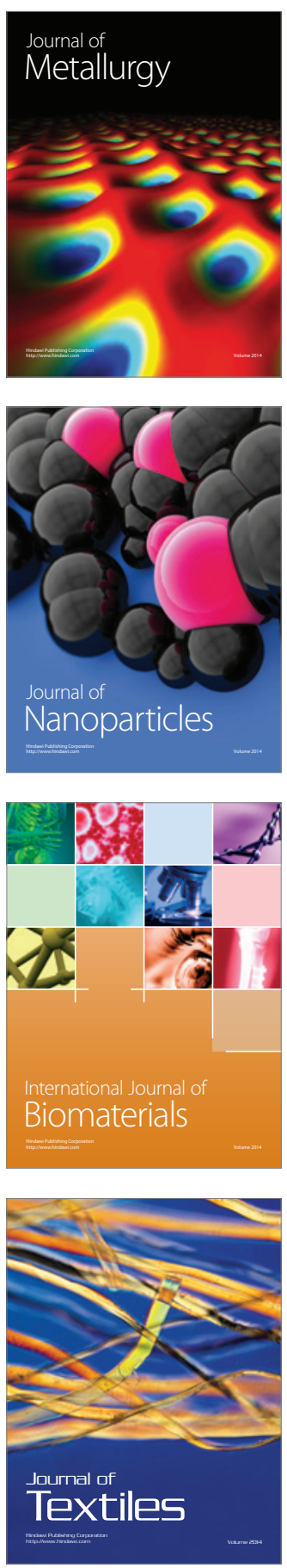